\title{
BILDER FRA FORTIDA? REPRESENTASJONER AV SAMISK KULTUR I SAMISKE MUSEER
}

\section{Bjørnar Olsen}

Europas representasjoner av andre kulturer har vert et av de sentrale tema $i$ den kritiske kulturforskningen siden slutten av 1970-tallet (f.eks. Said 1978, Todorov 1984, Young 1990, Hall 1992). Temaet ble for alvor brakt på banen da forfattere og intellektuelle fra den ikke-vestlige verden begynte à ta til orde mot de etnosentriske og rasistiske forestillinger som de mente preget Europas møte med "de andre». Dette igangsatte en lang rekke kritiske studier som viste hvordan vestlige stereotypier om kultur-og karaktertrekk var blitt sementert og gjort «sanne" gjennom politikk, vitenskap, litteratur, film, billedkunst og presse. Gjennom a sirkulere og stadig reprodusere stereotypier av andre, bidro disse ordskiftene og mediene til à essensialisere forestillinger om mentalitet, rase og kultur, og $i$ siste instans til a legitimere vestlig herredømme over andre kulturer.

Denne kritikken kom også til å ramme museet. Det moderne museet slik det fremsto i sine ulike disiplinære forgreininger på 1800-tallet, ble nemlig en viktig komponent $\mathrm{i}$ dette vestlige representative regimet. Sammen med vitenskapelige og skjønnlitterære tekster, og assosierte visuelle teknologier som fotografi og billedkunst, bidro museet til å forme andre kulturer som objekt for vestlig tilegnelse og kunnskap. For museet fikk begrepet «tilegnelse» dessuten en annen og mer konkret betydning gjennom den selvfølgelige rett man anså seg å ha til å kunne innsamle, forske på og utstille andre kulturer. Denne tilegnelsen var selvsagt relatert til makt; en makt bestemt av aktørenes lokalisering i den sosiale og kulturelle geografi og som avgjorde hvem som ble innsamlere og hvem som ble innsamlet (Clifford 1988:213).

Det er disse maktrelasjonene som i de siste årtier er blitt utfordret. Som ledd i ulike post-koloniale politiske og intellektuelle strømninger der representanter for urbefolkninger og land i 3. verden krever tilbake historie og tradisjoner fra vestlig besittelse, har vi i de siste årene vært vitne til hvordan vestlige museer og samlinger har blitt gjenstand for omfattende kritikk. De er ikke lenger sett på som ubestridte arenaer for kunnskap og opplysning, eller 
14 den automatiske og selvsagte hvileplassen for all verdens kulturarv (Hall 1982, Eyo 1996, Gilberg 1997). Det som kanskje kan forundre en, er at denne omfattende kritikken på ingen måte har resultert i en svekket posisjon for museet som institusjon. Tvert om, samtidig med at vestlige museer utsettes for økende kritikk og at det snakkes om en økonomisk, politisk og identitetsmessig krise for museene, ser vi at deres globale popularitet bare øker. Det virker nesten paradoksalt at en teknologi som er så nært forbundet med alt det som i dag hevdes å ha minst en fot i graven som autentisitet, store fortellinger, nasjonalstaten, ja selv historia - ustanselig koloniserer nye territorier (Macdonald 1996:1). Ingen ting synes heller å forhindre at denne teknologien, som i så stor grad har blitt assosiert med vestlig hegemoni, med kulturran og kolonialisme, med stereotype og reaksjonære kategoriseringer, i stadig større utstrekning tilegnes av dem som tidligere ble rammet og utdefinert av den. Og man kan med James Clifford spørre om hva det er som gjør museale praksiser så mobile, så anvendelige og så produktive i ulike områder? (Clifford 1997:217)

Sannsynligvis er det flere faktorer som spiller inn. Museets evne til å fryse og objektivisere det som er flytende og diffust, har gitt det et velfortjent ry som egnet teknologi i nasjonale og andre mer eller mindre forestilte fellesskapsprosjekt. Dets evne til å artikulere makt og tradisjon, og dens assosiasjon med kulturell prestisje og vestlig hegemoni, har på mange vis gjort museet til et slags kategorisk imperativ for den moderne væren. Ytterligere en faktor som kan forklare dets popularitet både blant undertrykkere og undertrykte er dets kommersielle betydning innenfor den globale turistindustrien, som standardisert, men samtidig eksotisk forskjellig mål for reisende på jakt etter autentiske kulturopplevelser (Rojek og Urry 1997).

I denne artikkelen skal jeg se nærmere på noen spørsmål som springer ut av denne museale globaliseringen: i hvilken grad bidrar den store veksten i nye nasjonale, lokale og "etniske» museer til at alternative representasjoner produseres? Blir bildet annerledes når et folk som tidligere er blitt representert av andre - og som regel sin undertrykker eller kolonisator - nå selv får rett og mulighet til utforme bildet av seg selv, sin kultur og sin historie? Eller blir dette bildet fortsatt basert på et nedarvet repertoar av utenforstående kategoriseringer slik at man risikerer å ende opp med en reproduksjon av eldre stereotypier? Er museet en uskyldig teknologi, en beholder som kan fylles med ny mening tilpasset ulike behov, eller er det så påvirket av sin egen virkningshistorie og sin tilknytning til europeisk mentalitet at ingen «annen» forståelse kan bli upåvirket? Kort sagt, kan museale representasjoner av «kultur» bli annet enn bilder fra fortida, et mausoleum for essensialistiske ideer om identitet og autentisitet? Kan de som Clifford (1997) optimistisk foreslår bli «kontaktsoner», møtesteder for ulike kulturer; markeder for dialog, kommentarer og forhandlinger om egen identitet og kultur?

Utgangspunktet mitt er de nye samiske museene som er blitt etablert i Norden siden 1980-tallet. Som del av et prosjekt om å forstå museenes rolle i ulike politiske og kulturelle kontekster besøkte jeg høsten 1998 de samiske hovedmuseene i 
Norge, Sverige og Finland for å få et inntrykk av hvilket bilde av samisk kultur de formidler til de besøkende. Før jeg konkret kommer inn på disse samiske institusjonene, skal jeg kort rekapitulere noen trekk ved museenes historiske framvekst i Europa.

\section{MUSEER OG REPRESENTASJON}

I dag framstår museene som en selvsagt og naturlig del av den moderne væren. Vi glemmer derfor lett at museet selv er en kulturell og historisk gjenstand som representerer verdier, diskurser og praksiser som er lokalisert i tid og sosiopolitisk rom. Som Walter Grasskamp (1994) har påpekt så framtrer de moderne klassifikatoriske prinsipper og de institusjonelle skillene mellom kunstmuseer og naturhistoriske museer, historiske og etnografiske museer, nasjonale og lokale museer, som så tilforlatelig og plausibel at vi forledes til å tro at de alltid har eksistert. Imidlertid har dette mediet sin egen historie av brudd og omveltninger, og er slik det fremstår $\mathrm{i}$ dag et produkt av en radikal endrings- og oppsplittingsprosess som ble styrt av opplysningstid og modernitet (Grasskamp 1994:72).

Museets opprinnelse blir gjerne i tradisjonell historieskrivning ført tilbake til 1400-tallet og den europeiske renessansen. Disse tidlige museene hadde imidlertid en annen funksjon og helt annen klassifikatorisk logikk enn det moderne museum, og de fremstår lett som usystematiske og kaotiske for det moderne blikk. De ble omtalt med for oss eksotiske navn som Wunderkammer, Studiolos, Verdensteater og Minnesteater, og var samlinger forbeholdt en sosial og kulturell elite. Deres represen- tative funksjon var også svært forskjellig verden, være et mikrokosmos som skulle verden, være et mikrokosmos som skulle synliggjøre Guds skaperverk i all dets mangfoldighet. Som Krzysztof Pomian har uttrykt det:

These were collections with encyclopaedic ambitions, intended as a minature version of the universe, containing specimens of every category of things and helping to render visible the totality of the universe, which otherwise would remain hidden from human eyes (Pomian 1990:69).

Med andre ord, samlingene skulle representere en slags miniatyrutgave eller «sammendrag» av verden.

Det moderne museet slik det fremsto i Europa på 1800-tallet hadde helt andre ambisjoner. Det var en del av den nye «offentlige sfære» (Habermas 1971), og inngikk $\mathrm{i}$ et opplysende prosjekt rettet spesielt mot de brede lag av folket (Plessen 1994, Vindheim 1994). Samtidig ble fokus kraftig snevret inn. Det var ikke lenger "universet", men nasjonen og statens territorium som framsto som rammen rundt samlingene (i noe større målestokk for de med imperiets ambisjoner, jfr. British Museum). Museet var et av de rom der nasjonen kunne presenterer seg selv som et «innbilt fellesskap" (Anderson 1983, Prösler 1996:32). Tilkomsten av nasjonalmuseer rundt i Europa i forrige århundre eksemplifiserer betydningen av dette rommet, som en metaforisk representasjon av nasjonen som et historisk og territorielt definert fellesskap. Gjennom en kløktig iscenesetting av folk, historie og territorium, antok den utstilte nasjonen sin egen substans og realitet som man kunne betrakte, lære av og eventuelt sloss 
16 for (Macdonald 1996:7).

Sentralt i dette nasjonale identitetsprosjektet var også Europas og den vestlige kulturs identitet. Samtidig som de nasjonale museene talte om innbyrdes forskjellighet, så var det innenfor rammen av et fellesskap, en felles modell (som jo nettopp museet utgjorde) og en grunnleggende enighet om at visse prinsipper og karakteristikker gjaldt eksklusivt for dem. På tross av ulikhetene mellom nasjonene var de tross alt representasjoner av vestlige nasjoner og historiske folk, og fundamentalt forskjellig fra de som ikke oppfylte dette kriteriet. Gjennom sin radikale omstrukturering på 1800-tallet, kom museet derfor ikke bare til å visualisere og naturalisere nasjonen, men også kontrasten mellom en elite-serie av historiske nasjoner og de som på et tidspunkt hadde gått seg fast $\mathrm{i}$ ulike lavere divisjoner.

Konkret kom dette til uttrykk gjennom separasjonen mellom museer eller avdelinger som presenterer de europeiske folks kultur og historie, og de som gir etnografiske presentasjoner av primitive, primært ikke-europeiske folk. En separasjon som kan uttrykkes som et skille mellom folk med og folk uten historie (Wolf 1982, Worsley 1984). Dette skillet, som kom til å sette varige spor i kulturvitenskapene og museenes arbeidsdeling, hadde sin bakgrunn i forestillingen om at visse folk, primært de europeiske statsbærende folk, var dynamiske og hadde evne og vilje til forandring, dvs. til å skape historie. Andre grupper, som urfolk og etniske minoriteter, ble derimot oppfattet som tidløse og uten forandring. Slike statiske folk kunne analyseres uten den tidsdimensjonen som man anså som fundamental for historiske folk. De ble derfor delegert det fagområ- det som beskjeftiget seg med slike primitive, ikke-europeiske samfunn: etnografien.

Det er i lys av dette at vi må forstå samene som etnografiens domene i Norden, og den dypt rotfestete dikotomien mellom en norsk/svensk historie og en samisk etnografi. På museet fant derfor samene sin korrekte museale representasjon i de etnografiske utstillingene, mens majoritetsbefolkningen havnet i de historiske. Dette la grunnlaget for en etnografisk genre som helt opp til i dag har dominert museale framstillinger av samisk kultur. En genre basert på at den samiske kultur har en tradisjonell, idealtypisk form som kan stykkes opp i biter som religion, materiell kultur, skikker, økonomi, bosetning, osv., og som kan presenteres uten en historisk dimensjon som viser hvordan forhold har tilkommet eller endret seg over tid. Endring blir her ofte et spørsmål om modernitet og oppløsning av kultur, om tap av identitet. Denne genren kom ikke bare til uttrykk i museene, men kanskje i enda sterkere grad i de skrevne etnografiske monografiene om samene, fra Gustaf von Düben til Phebe Fjellström. Både de skrevne og museale framstillinger av samisk kultur sto utenfor det system av tid og endring som strukturerte de historiske verkene og de historiske utstillingene i epoker.

Det er opp mot denne historiske bakgrunnen, denne museale «virkningshistorien", jeg vil vurdere det bildet som presenteres av samisk kultur og fortid på dagens samiske museene. I hvilken grad har framveksten av egne samiske museer bidratt til å endre og bestride det etnografiske bildet av samisk kultur som statisk og døende? Hvordan håndterer man oppgaven med selv å skulle forvalte representasjoner av 
egen kultur og historie i ei omskiftelig samtid?

\section{SAMISKE MUSEER: BILDER AV EGEN VIRKELIGHET?}

På den Nordiske Samekonferansen i Inari i 1976, ble det nedsatt et museumsnevn som utarbeidet en tiltaksplan for samiske museer i Norden. Denne skisserte noen hovedprinsipper for samisk museumsarbeid og definerte noen viktige kriterier for hva som kan kalles et samisk museum (Nilsson 1982:88-89). Disse innebar blant annet at samer har den faglige og administrative ledelsen, at samisk kulturhistorie skal utgjøre hovedtema, at samekulturens tradisjoner skal respekteres og studeres ut fra en samisk synsvinkel, og til sist at museet skal ligge i et samisk kjerneområde. I den samme utredningen ble det poengtert nødvendigheten av at det innenfor hver av de tre nordiske nasjonalstatene med en samisk befolkning ble etablert et samisk hovedmuseum. I dag er dette blitt en realitet gjennom de samiske museene i Karasjok, Jokkmokk og Inari, og det er også disse tre som danner utgangspunkt for denne artikkelen. Det skal nevnes at det spesielt i Norge har tilkommet flere andre samiske museer i de senere årene, slik at i vi i dag blant annet har museer med spesielt ansvar for den sørsamiske, den lulesamiske, den østsamiske og den sjøsamiske kulturen i Norge.

Framveksten av de samiske museer må sees i lys av de siste 30 årenes politiske bevisstgjøring blant samene. Slutten av 1970-tallet og begynnelsen av 1980-tallet ble et avgjørende vendepunkt for samenes status som etnisk minoritet i Norden, ikke minst i Norge (Bråstad Jensen 1991, Eid- heim 1999). Dette vendepunktet var i betydelig grad relatert til kampen mot utbyggingen av Alta-elven. Samenes politiske organisasjoner, først og fremst Norske Samers Riksforbund (NSR), maktet å gjøre denne til en strid der samenes rettigheter som urbefolkning i nord kom i fokus. Samiske politikere og intellektuelle så også sin kamp som del av en større antikolonialistisk bevegelse, der representanter fra den 3. og 4. verden krevde tilbake land og historie fra vestlig besittelse og retten til å snakke for seg selv. I de strategier som NSR og de samiske aktivistene valgte sto synliggjøring sentralt, man ville ødelegge bildet av Norge som et etnisk og kulturelt homogent samfunn (Stordahl 1996). Gjennom en vellykket strategi med å gjøre seg selv synlig i media, på universitetene og i politikken, maktet de samiske organisasjonene å få rettet søkelyset mot samenes kritiske situasjon. Og selv om man i 1981 tapte striden om Alta utbyggingen ble de politiske gevinstene betydelige.

Framveksten av egne samiske museer kan vanskelig isoleres fra disse etno-politiske prosessene. Disse institusjonene har blitt skapt ut fra ønske om å styrke samisk kulturell identitet, å gi stolthet og trygghet om egen kultur, og selvsagt for å bevare og presentere den samiske kulturarv (Teigmo 1976, Eira 1988). Museene har blitt viktige møteplasser i lokalsamfunnet, og tjener også som arenaer for andre aktiviteter som konserter, møter, kurs, osv. Både gjennom sin rent fysiske tilstedeværelse, i form av selve museumsbygget, og gjennom sine utstillinger kan disse museene sees som del av en mer omfattende politisk strategi om å gjøre samisk kultur og historie synlig, både for samene selv og storsamfunnet. De skal også vise hvordan 
samene gjenvinner kontroll over representasjoner av egen kultur og at man tar tilbake historie og tradisjon fra majoritetssamfunnenes besittelse.

\section{Sámiid Vuorká-Dávvirat/De Samiske Samlinger, Karasjok, Norge}

De Samiske Samlinger i Karasjok har vært et hovedmuseum for samekulturen i Norge siden 1975, men fikk i 1995 status som nasjonalmuseum. Selve museumsbygget er fra 1972, mens basisutstillingen er fra midten av 1980-tallet. Utenfor museet er det et friluftsanlegg med samiske boligtyper, båter og fangst-innretninger. Basisutstillingen er delt $\mathrm{i}$ ulike deler der samiske næringer, duodji og draktskikker er de viktigste. I tillegg er det en kort forhistorisk del og en del viet samisk religion. Utstillingen er bygget opp med gjenstander, fotografier og en del montasjer eller installasjoner - mens klassiske museale iscenesettinger er fraværende. Mindre gjenstander er montert på reinsdyrskinn spent opp i veggmontre. Utstillingen er formgitt av den samiske kunstneren Iver Joks og hans kunstneriske uttrykk er et viktig visuelt element ved utstillingen.

Utstillingen gir et bilde av en førmoderne samisk kultur og i sitt visuelle innhold fraviker den lite fra den etablerte etnografiske genren ved de større skandinaviske museene. Samekulturen er splittet opp i ulike deler: økonomi, ressurser, håndverk, religion - samekulturen ved kysten, skogssamer, elvesamer og reindrift. Pulker, jakt- og fiskeutstyr, beinskjeer, kniver, en sieidi og en noaide-tromme presenteres uten noen bemerkninger om endring eller tid, annet enn at de tilhører en ikke nærmere spesifisert, tradisjonell fortid (fig. 1).
Tekstene i utstillingen har imidlertid et klart politisk budskap. Fokus er på lidelse og tap, og hvordan samene har blitt offer for kolonisering og undertrykkelse fra norske myndigheters side. De kan leses som et uttrykk for den politiske situasjonen på begynnelsen av 1980-tallet og de strategier som da ble rådende i den etnopolitiske bevegelsen. Her inngikk blant annet vektlegging av indre enhet og solidaritet, samt betoningen av den klare kontrasten til majoritetssamfunnet. Følgende tekst med overskriften Det samiske samfunn er i så måte typisk. Her framheves først den samiske kulturens grunnidéer:

I en kultur finnes visse grunnidéer som er forholdsvis stabile over tid og som menneskene må underordne seg. Grunnidéene kommer fram i språket, duodji (kunst og håndverk), tradisjoner, samfunnsformer og i næringslivet. All utvikling og endring vurderes i forhold til grunnidéene.

En av grunnidéene har vært at mennesket er en del av naturen. Av dette følger respekt for naturen. Sjølberging som folk og at mennesker er likestilte og skal samarbeide istedenfor å undertrykke hverandre, er andre samfunnstrekk. "Siehtadit" - å forhandle er et samisk ord, men ikke «soahtat" - å krige.

Så følger et tekstavsnitt som understreker at de interne forskjellene $\mathrm{i}$ den samiske kulturen er små og bare omfatter «en viss variasjon i arbeidsformer, gjenstander, ord og uttrykk». Det pekes på at disse «lokale særdrag» ofte "feilaktig» utlegges som mer grunnleggende forskjeller, og som kanskje kunne så tvil om samene var ett folk. For å fjerne denne betones i stedet kontrasten til og uavhengigheten av de omgivende majoritetsfolkene, og de tette sosiale nettverkene og enheten innad i den samiske kulturen: 


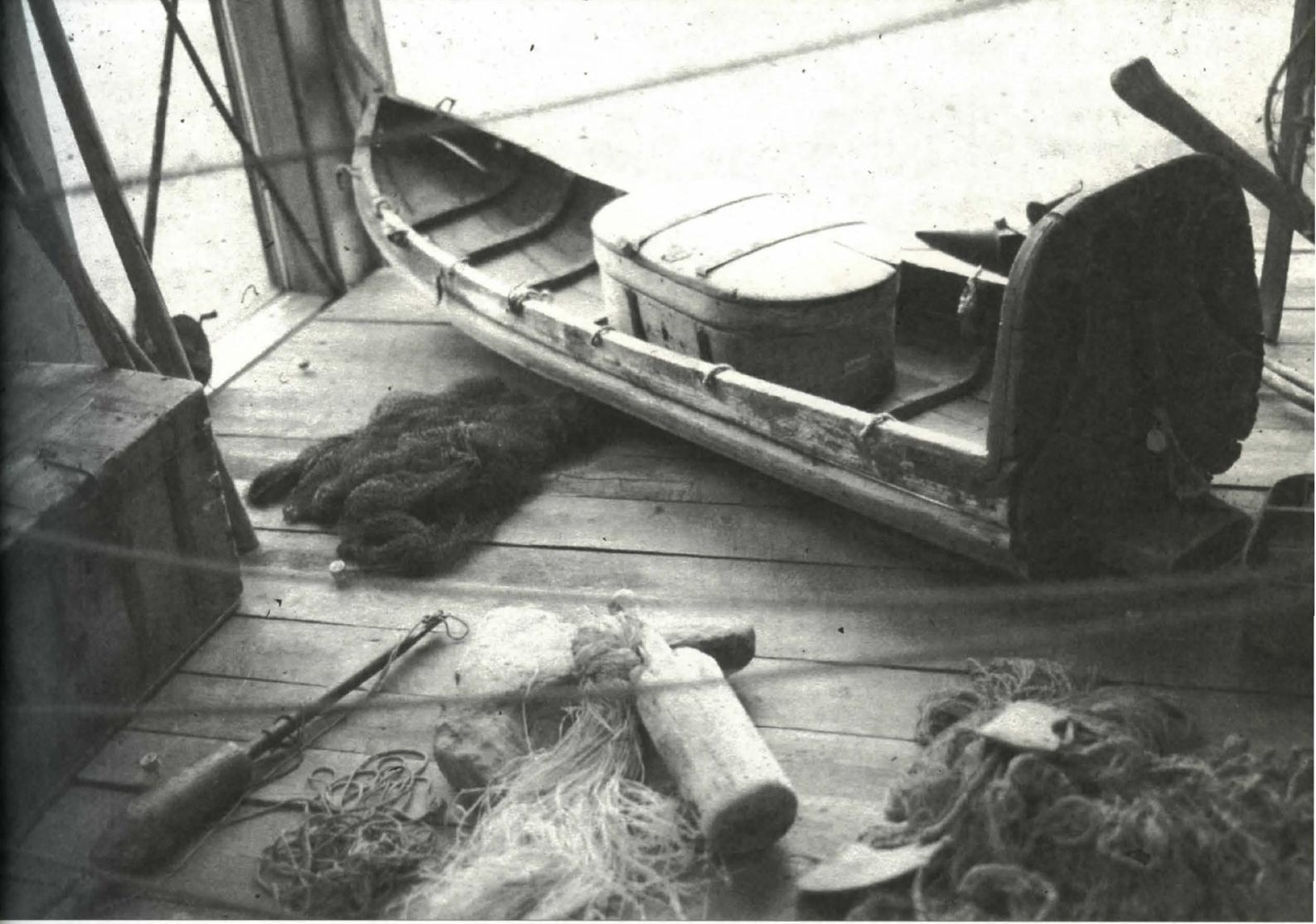

1. Ekte samisk kultur? (De Samiske Samlinger, Karasjok)

Den samiske kulturen var såpass ulik de omkringliggende majoritetsfolkeslag at mest mulig sjølberging var nødvendig for ikke å bli «livegne» eller miste sitt særpreg og selvfølelse. Arbeidsbytte mellom slektninger og bekjente, og mellom kyst og innland var alminnelig. Svært utvidete slektskapsforhold - «verde» (gjestevenn) - giftemål mellom ulike næringsgrupper og over riksgrensen, dåpsvitner, fosterforeldre, utflyttinger, språk og håndverk, er andre trekk som har opprettholdt de sosiale forbindelsene.

Til slutt blir kontakten med majoritetsfolkene omtalt i negative termer og som den primære kilde til kulturell destruksjon, endring og oppsplitting:

Omkringliggende majoritetsfolk, ... , har i større eller mindre grad opp gjennom tidene kunne gjøre inngrep i samekulturen, bl.a. ved skattlegging, lover, naturinngrep, gruppeinndeling av samer og hets mot folkegruppen ... Samer har måtte endre sin livsform og bøte på at naturen ble innskrenket eller forringet, enten ved å la den hvile, ... eller endre livsform som å øke tamreinholdet og vektlegge jordbruk og fiske. Ulik grad av majoritetsinngrep og påvirkning har etterhvert medført en del ulikhet blant samer, men fortsatt finnes fellestrekk som synet på natur og mennesker. ...

Tekstene inneholder også elementer av selvhevdelse gjennom å betone historiske utsagn om samers dyktighet og ferdigheter. I tekstavsnittet Samekulturen ved kysten heter det således:

I eldre tider berettes det at samer var de dyktigste på sjøen og at de var de beste båtbyggerne. Flere vikinger fikk laget båter hos samer. .... Samer drev også fangst av hval og sjødyr. Fram til 1800-tallet regnes samene å ha den største ekspertisen også her. ...

Svært mange av tekstene i utstillingen synes å være komponert etter samme plot: først gis en beskrivelse av hvordan ting 
BJøRNAR OLSEN

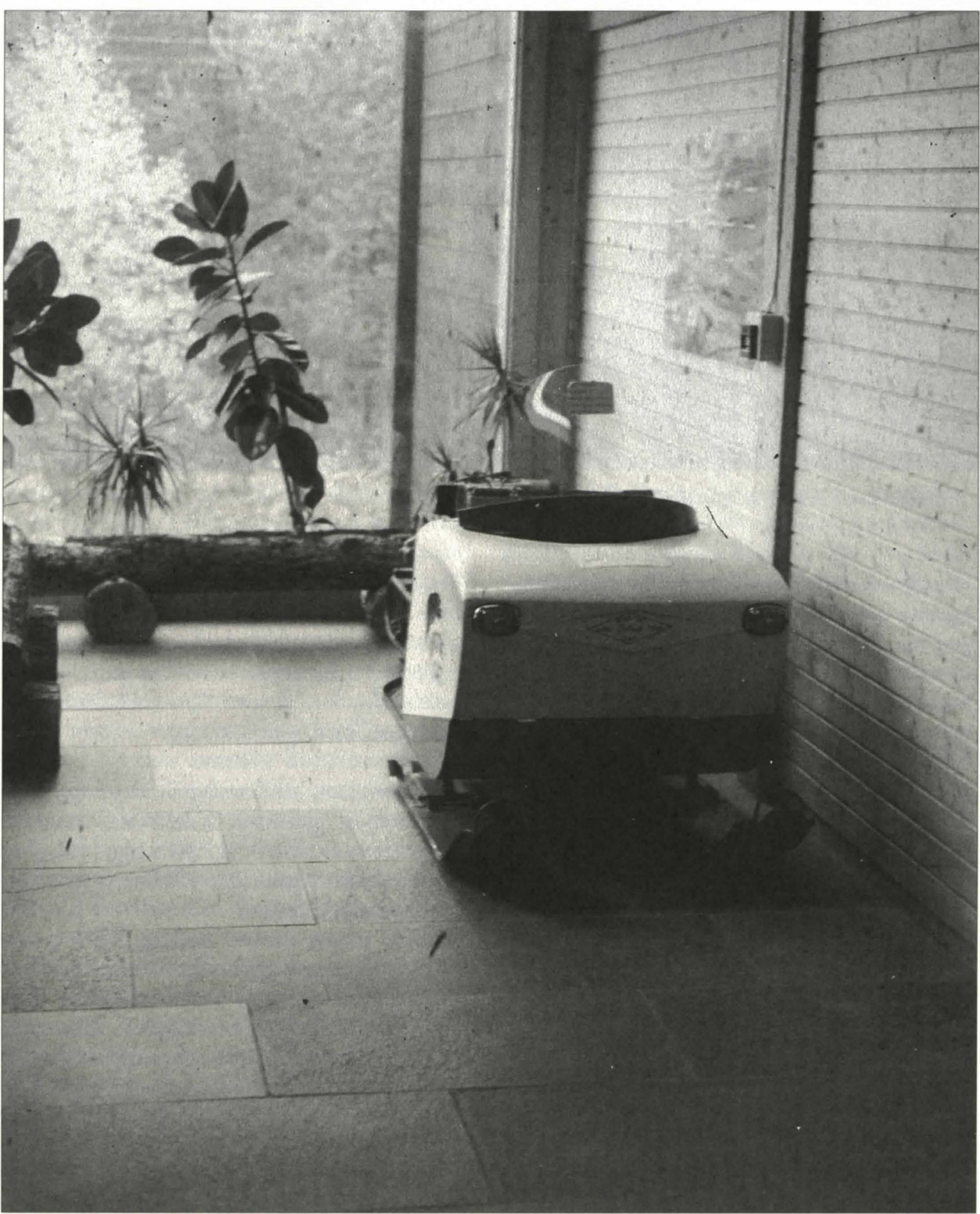

2. Uekte samisk kultur? (De Samiske Samlinger, Karasjok) 
opprinnelig var (det tradisjonelle samiske samfunn), så følger en avsluttende del om inngrep, modernisering, tap og ødeleggelse. Om hvordan ting gikk galt som følge av inngrep utenfra. Denne strukturen gjenfinnes i teksttemaer som Jakt- og fangstkulturen ("...Røvertokter og skattlegging av samer var derfor lønnsomt og medførte snart utryddelse av flere dyreslag»), Ferskvannsfiske ("...Idag har det minsket med fisk både i vann og elver p.g.a. for mange fiskere utenfra"), Skogen ("...idag har staten tilegnet seg retten til skogen i Finnmark") og Samekulturen ved kysten ("..mange av disse [spesielle kystsamiske kulturtrekk] har etterhvert forsvunnet p.g.a. et stadig sterkere press utenfra»). Utstillingen selv har imidlertid få spor av modernitet og de endringer den nye tid brakte. Ett av de få, en snøscooter fra 1964 - er plassert utenfor selve utstillingsrommet (fig. 2). Vi finner den i enden av en korridor, vendt som om den er kommet gjennom vinduet fra verden utenfor. Snøscooteren kan leses som et symbol på den nye tids forurensing av samisk kultur. Den symboliserer de destruktive kreftene fra verden utenfor, og er derfor romlig ekskludert fra den "egentlige» samiske kulturen.

Nesten samtlige gjenstander i denne utstillingen er "tradisjonelle» eller tilårskomne. Bildet av en ubevegelig, tradisjonell fortid underbygges av store veggmontasjer der helleristninger og symboler fra samiske trommer er sammenstilt. De framstår som ett uttrykk fra en felles ubevegelig fortid uten fokus på kronologiske distanser. Forandring, brudd, blir implisitt framstilt som et konsekvens av moderniteten. Før rådet stabilitet og tradisjon.
Siida Oahpis/Siida Inarian Saamelaismuseo, Inari, Finland

Dette er det mest moderne av de tre samiske hovedmuseene, og ble åpnet sommeren 1998. Et lite samisk friluftsmuseum var imidlertid anlagt her allerede i 1959, og disse anleggene er nå inkorporert i det nye museet. Museet er del-finansiert gjennom EU's region-program. Den store og moderne museumsbygningen, som også rommer et informasjonssenter om finsk Lappland, avviker sterkt fra det "tradisjonelle" designet som preger andre samiske museumsbygg. På mange vis er også tilnærmingen til samisk kultur svært forskjellig fra den vi finner på museet $\mathrm{i}$ Karasjok. Dette ikke bare rent utstillingsteknisk, ved at moderne audiovisuelle teknikker er mye mer framtredende, men også ved å anlegge et nokså strengt vitenskapelig og økologisk funksjonalistisk perspektiv på samisk kultur. I den skrevne guide-boken til museet blir dette perspektivet presentert på følgende vis:

The main exhibition reflects an approach to culture adopted by cultural and human ecology. The culture of the Sámi is seen as being linked to the natural environment, climate and seasons of Lapland. The cultural system, conceived through a series of human choices, has produced a pattern of behaviour encompassing the physiological, material, social, and spiritual domains which makes it possible for humans to survive in the demanding conditions of the arctic environment (Pennanen 1998:3)

Utstillingen er to-delt med en kort innledende utstilling om natur og kulturhistorien, og en hovedutstilling som presenterer samisk kultur. I den første presenteres utviklingen fra istiden til nåtiden. Dette er gjennomført ved at det langs veggene i et 


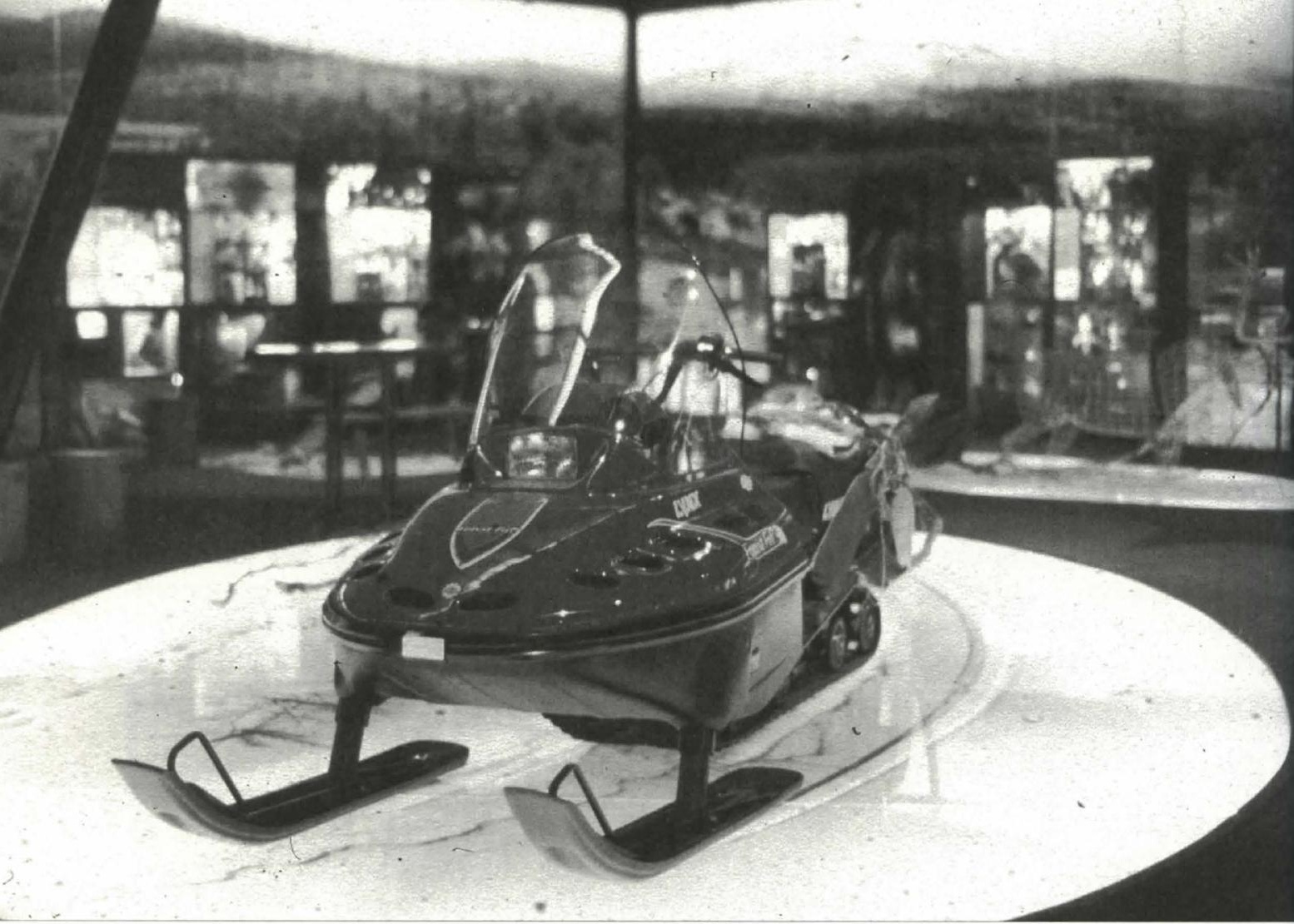

3. Fotografiene denne og neste side: Modernitet og ironi? (Siida Inarin Saamelaismuseo, Inari)

mindre rom er laget en tidsløype med bilder, tekster og gjenstander i tre nivåer. I bunnen finnes naturhistorien, den geologiske, klimatiske og vegetasjonshistoriske utviklingen. Over denne finner vi Samelands historie, som framstilles punktvis fra den tidligste bosetningen og fram til viktige "hendelser» for samene $\mathrm{i}$ dette århundret. Den øverste del av montasjen er viet "verden" i form av bilder fra Egypt, Stonehenge, og etterhvert med kjente historiske personer. $\mathrm{Vi}$ blir her presentert for en slags "snap-shot"-historie, uten kontekst eller sammenhenger, men som likevel kommuniserer et sentralt budskap om at naturen ligger i bunn - er grunnlaget alt hviler på. Gjennom å plassere samisk kultur mellom den store sivilisasjonshistorien (kulturen?) og naturhistorien, blir man lett (for)ledet til å lese denne som stående mellom kultur og natur.

Hovedutstillingen tydeliggjør enda kla- rere den økologiske tilnærmingen. Den samiske kulturen er plassert på en plattform i et stort firkantet rom. Rommet og veggene utenfor plattformen utgjør naturen; hver av veggene er enorme lysbildemontasjer av de fire årstider. Denne romlige arrangeringen av utstillingen, der samisk kultur er omgitt av natur, er et viktig retorisk virkemiddel for å få fram det økologiske budskapet om en kultur styrt eller underlagt naturen: "The layout has been organized so that the exhibition concerned with the environment follows the outer walls and encircles the cultural exhibition" (Pennanen 1998:3). Kulturen er plassert i naturen. De ulike årtidene er gitt tematiske og tildels poetiske titler, vinteren "survival in the dark and cold", våren "the dawning of a new day", sommeren "the season of growth", mens høsten er redusert til "preparations for winter".

Utstillingen gir et vitenskapelig, nær- 

met finnes bare en permanent utstilling et tablå som framstiller møtet mellom en birkarl og en samefamilie på 1500-tallet (fig. 4). Birkarlen krever inn skatt og ruver truende i sin hvite skinnpesk over en knelende liten samefamilie. Barnet gjemmer seg bak moren, som igjen gjemmer seg bak ryggen på husfaren som byr fram fangsten til birkarlen.

Det enslige tablået slår an tonen i utstillingen ved at den metonymiserer samisk historie som en historie om utbytting, inngrep og undertrykking. Dette understrekes av tekstene som svært ofte har et klart og bevisst politisk budskap til publikum. De utfordrer den besøkende til refleksjon, gjennom å reise spørsmål som angår fortid og nåtid, og spør hvorfor ting har blitt slik de har blitt i dag. Teksten tilhørende tablået med birkarlen avsluttes med følgende spørsmål: «så var det. Hur är det idag?».

Fra Gamla hallen ledes man gjennom en tunnelformet passasje kalt Tidens gång, som skildrer kulturelle endringer på Nordkalotten. Her er historien framstilt som en tidsløype gjennom tekster og skiftende representanter for fortidas mennesker. I begynnelsen er alt fred og idyll. Mennesket høstet av naturen, «lax i älven, älg i skogen», «renen ga grunden för liv». På 1500-tallet begynner det imidlertid å rakne:

Efterhand hittade främlingar hit, folk som förbannade kölden och mörkret. De såg skogens djur som rikedomar. Drömde om silver i bergen. De kom allt fler och allt oftare. En del av dem blev berömda, fick sina namn i böcker. På 1500-talet kallades de birkarlar. De finns här idag. Och det finns en del kvar att hämta här, säger de. Hoi hái!
Passasjen Tidens gång leder videre til hoveddelen av utstillingen. Denne er romlig organisert som en innhegning for tamrein, med en sentral "hage" i midten og åtte rom med utstillinger som radierer ut fra denne. Disse dekker ulike natur- og kulturhistoriske temaer, og samekulturen er sterkest representert i Sápmi (om samisk liv, tro og myter), Att reda sig (om samisk hushold) og $P a ̊$ väg (om transport og forflyttninger i fangstmarken). Den mest tankevekkende av disse er Sápmi som både tekstlig og materielt framstår som en klar politisk kommentar til fortid og nåtid. I guideheftet blir denne introdusert på følgende vis:

Vi har inte haft några kungar eller generaler, vi har inte behövt någon riksdag. Vi har inte byggt stora städer att samlas $i$, ej heller stora monument att samlas kring. Vi har alltid levt utspridda bland dessa våra fjordar, skogar, älvar och sjöar. Bland dessa vidder har våra förfäder levat utan att behöva förklara detta för någon. Idag ifrågasätts vår rätt till landet. Men vi har ju inga lagböcker, de har aldrig behövts. De lagböcker som dömer våra liv idag är skrivna av främlingar i de stora riken som inte bara omger oss, utan också trängt sig in i vårt land. Som lär oss andra språk, andra sätt att tänka, ett annat liv. Men trots allt detta hävdar vi att Sápmi är vårt, det är vårt liv. Vi begär rätten och möjligheter att forma vårt liv och vår framtid så som vi vill att den skall se ut.

Rommet er holdt i fargene til det samiske flagget som troner over et stort bilde av det svenske sametinget. En montasje over livet i Sápmi i dag («vi är inte många»), for femti år siden («de är fler än oss nu») og for 100 år siden («här lever nästan bara vi»), beretter en historie om hvordan samene mister kontroll over sin egen til- 



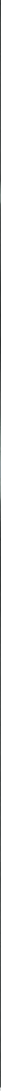

5. Bilder fra fortida? Den «etnografiske genre» representert på Ajtte. (Ajtte. Svenskt Fjäll- och Samemuseum, Jokkmokk)

utenfra. Det skapes et perspektiv der isolasjon, stabilitet og tradisjon, dvs. de gode tider, settes opp mot kontakt, endring og modernitet, de dårlige tider. Budskapet som dermed lett leses ut av dette blir at så lenge vi var aleine gikk alt bra - mens kontakt, handel og tilflytting er kimen til kulturell destruksjon og fremmedgjøring.

\section{MUSEER, FORTID OG IDENTITET}

For samene, som for andre urbefolkninger rundt i verden, er det å beskytte og ha kontroll over sin egen kulturarv en viktig del av nåtidspolitikken. Alle de tre museene vi har sett på her gjør en utmerket og viktig jobb i så måte. Imidlertid kan det reises spørsmål ved det bilde de gir av samisk kultur og historie, og i hvilken grad dette blir forskjellig fra de etnografiske representasjonene av samene som vi kjenner fra de store nordiske museene.
En under-tekst som i større eller mindre grad kan leses ut av utstillingene ved alle de tre museene, er at den egentlige samiske kulturen bare eksisterte $\mathrm{i}$ fortida. Dermed står man i fare for å reprodusere de etnografiske mesterberetningene, der samene tilskrives en statisk og tradisjonell (tapt) kultur. Perspektivet blir lett at moderniteten ikke har noe å tilby urbefolkninger og minoriteter annet enn tap og forurensing, og at den eneste museale måten å forholde seg til globalisering og det moderne liv blir taushet, fordømmelse eller ironiske kommentarer. Den egentlige og ekte samiske kultur blir alltid fortid, og de samiske museenes fremste formål blir å redde og bevare dette kulturminnet. Deres funksjon blir, for å låne Cliffords ord, et «redningsarbeide»:

an act of salvage that repeats an all-too-familiar story of death and redemption. In this pervasive 
allegory the non-western world is always vanishing and modernizing - as in Walter Benjamin's allegory of modernity, the tribal world is conceived as a ruin» (Clifford 1988:202)

Det museale prosjektet om falmende og døende kulturer hvilte på forestillingen om noe ubevegelig opprinnelig, forut for kontakt, et fastpunkt som moderniten kunne måles i forhold til. Den etnografiske sjangeren skapte sin egen virkeliggjøring av denne forestillingen. Det er et paradoks at i den grad den blir reprodusert i dagens samiske museer, så kan det lett underbygge det reaksjonære museumsbildet som så lenge har vært tegnet av samer og andre urbefolkninger som alltiddet-samme tradisjonelle samfunn. Det er i relieff av dette fengselet av tradisjon og autentisitet at enhver endring lett blir sett på som forurensing og tap av identitet.

Et viktig arkeologisk og historisk korrektiv til denne myten om det tradisjonelle samiske samfunn vil være å vise hvordan også de samiske samfunn har vært i mer eller mindre konstant endring. De samiske samfunn vi gjerne omtaler som «tradisjonelle», og som er belagt i skrevne kilder fra 16-, 17- og 1800-tallet, hadde selv vært gjenstand for omfattende endringer og påvirkninger, de var både innbyrdes ulike og var svært forskjellig fra tidligere samiske samfunn. På samme vis som samiske samfunn i mellomalderen var forskjellig fra samiske samfunn i jernalderen. Materiell kultur, samfunnsrelasjoner, bosettingsmønster, religion og mentalitet, har hele tiden endret seg. Endring er derfor ikke et resultat av modernitet, og kontakt med andre samfunn og kulturer har vært en del av også tidligere samfunns eksistensvilkår.

\section{NYE TIDER, NYE BLIKK}

Det ville være helt feil å etterlate det inntrykk at slike forhold ikke erkjennes eller diskuteres ved dagens samiske museer, eller at det ikke gjøres aktive forsøk på å bestride det etnografiske bildet av samisk kultur og historie. Visse tendenser til dette finner vi på Ájtte, som på mange vis har lyktes med en utfordrende og problematiserende utstilling. Jeg skal imidlertid avslutningsvis få nevne to andre samiske museer, begge i Norge, som i skrivende stund arbeider med utstillinger som jeg tror vil utfordre rådende forestillinger om samisk kultur.

Det ene av disse er Árran Julevsáme guovdásj/lulesamisk senter på Drag i Tysfjord. Her planlegges det nå en stor ny basisutstilling der det moderne samiske samfunn er et av hovedtemaene. I prosjektskissen til denne utstillingen kan vi lese at man ønsker å fokusere på det samiske samfunn som tilpasningsdyktig og fleksibelt, stikkordene er mangfold og endring. Man ønsker å ta hensyn til at samiske kulturtrekk hele tiden skapes gjennom moderne kunst og design, musikk, litteratur, forskning og utdanning. Samiske kulturtrekk er med andre ord noe som kontinuerlig skapes, ikke bare noe man skal «redde» eller "vedlikeholde». Det påpekes at samisk kultur tar hensyn både til den globale utvikling og tradisjonell kunnskap og verdier. En av de fremste målsetninger med utstillingen er å bestride essensialistiske og stereotype oppfatninger av det "ekte samiske». I en beskrivelse av utstillingen heter det derfor:

Gjennom vår utstilling vil vi formidle at det samiske samfunn aldri har vært statisk, men at det alltid 
28 har vært - og vil fortsette å være - i kontinuerlig endring. Det samiske samfunnet var/er heller ikke et passivt samfunn, men har vist at det kan omstrukturere seg og tilpasse seg ytre endringer og nye situasjoner. Samene har dessuten vist at de kan mobilisere motstand mot politiske og økonomiske overgrep. Studier av samisk kulturhistorie viser at det samiske samfunn aldri har vært en isolert eller "stagnert" kultur. Akkurat som de øvrige samfunn i Fennoskandia har adoptert kulturelle elementer fra samene, har også de samiske samfunn alltid vært åpne for impulser utenfra. Det er derfor ikke noe "usamisk" fenomen at f.eks. Tysfjordsamene fra omkring århundreskiftet gradvis går over fra gammer til tømrete hus. $\AA$ jobbe som datakonsulent eller oljedriller er ikke mer atypisk samisk enn det er atypisk norsk. At samene er en del av det moderne samfunn er verken "usamisk" eller unaturlig (Árran 1998, s. 5)

Kontrasten mellom dette utsagnet og det tidligere refererte tekstutsnitt fra $\mathrm{De}$ Samiske Samlingers utstilling er slående, og gjenspeiler utvilsomt noen av de endringer som har skjedd teoretisk og politisk, globalt og lokalt, på 1990-tallet.

Denne viljen til å nærme seg nåtid og endring, finner vi også i det utstillingsarbeide som nå pågår på et annet museum: Várjjat Sámi musea/Varanger Samiske Museum i Varangerbotn, Nesseby kommune. Her arbeider man nå med en ny basisutstilling som har til hensikt å skape en dialog mellom fortid og nåtid, og der også nåtidig samisk identitet framstilles som omskiftelig og fleksibel. En del omfatter samisk reindrift $\mathrm{i}$ fortid og nåtid. På en enkel måte blir her fortida kontrastert med nåtida, men uten nostalgi og romantikk. I dag bruker alle reingjetere plastlasso fordi den funksjonelt er de gamle overlegne. En plastlasso, en satelitt-navigator og en snøscooter er i dag like mye del av samisk kultur, som tre- og beinredskap var det tidligere. At endring ikke er noe som bare foregår i dag vises gjennom et langt tidsperspektiv som vektlegger nettopp forandringene og skiftningene i menneskenes 10000 -årige liv ved Varangerfjorden. Det vises også i rekonstruksjonen av en sjøsamisk boplass fra 1800-tallet, hvor brytningen mellom gammelt og nytt står sentralt. Her er både den tradisjonelle torvgammen, men også tømmerhuset som mange sjøsamer etterhvert flyttet inn i. Det steinsatte ildstedet erstattes av jernovnen, og boplassen framviser et miks mellom nytt og gammelt, lokalt og fremmed, som trolig "alltid" har preget samisk kultur.

Det man forsøker med disse utstillingene på Árran og på Varanger Samiske Museum, om jeg har forstått det rett, er å unngå den litt for vanlige museale praksisen med å kontrastere ei ekte, tradisjonell innfødt fortid, representert ved autentiske objekter, mot en modernitet som lett får elendighetens skjær over seg, og hvor den eksisterende kultur gjennom sin forurensing fra moderne vestlig kultur oppleves som mindre «ekte» (sml. Riegel 1996:98). Som nevnt var ikke kontakt og utveksling med andre samfunn noe som var fremmed for samisk kultur i tidligere tider. Tvert om. På de store nordsvenske offerplassene fra vikingtid og mellomalder ofret samene arabiske, tyske og engelske mynter; smykker fra Volga, Ladoga og Gotland fulgte de døde til gravene i Varanger, og på 1700-tallet satt sjøsamene i Kvænangen i sine gammer og røkte tobakk i hollandske krittpiper (Zachrisson 1984, Schanche 1997, Grydeland 1996). Forestillingen om isolerte og rene kulturer er her som andre 
steder en myte. Som antropologen Appadurai har uttrykt det, "natives, peoples confined to and by places to which they belong, groups unsullied by contact with a larger world, have probably never existed" (Appadurai 1988:39).

Da jeg besøkte Varanger Samiske Museum i slutten av september var det en vandreutstilling av pakistanske tepper og kunstgjenstander der. Kanskje er det å gjøre rom også for det kulturelt fremmede på et samisk museum nettopp et uttrykk for et ønske om å se samisk kultur som del av en globalisert verden. Det jeg oppfatter at disse to sistnevnte samiske musene ønsker å framvise, er ikke en historie om en rein, uberørt kultur, men mer om kreativitet og bricolage $\mathrm{i}$ en globalisert verden. De forteller historier om samisk kultur og identitet som en kontinuerlig pågående prosess av menneskelig virke og skaping.

\section{SUMMARY}

On the representation of Saami history in Saami museums

During the last three decades, a number of Saami museums and cultural centers have been established in northern Fennoscandinavia. These institutions are assigned an important role in the ongoing process of Saami cultural and ethnic revival. This paper focuses on how Saami culture and history are represented at these «indigenous» museums: what stories are told and what images of Saami cultural and ethnic identity are produced or reproduced. An examination of the three main Saami museums in northern Fennoscandinavia reveals representations that conform to a surprising degree with the ethnographic master narratives of the Saami as a never changing traditional society. The real, genuine Saami life is always in the past and unchanging.
Change is more or less uniformly portrayed as a 29 product of the evil forces of modernity involving cultural contamination and loss of identity. The final section of the paper reports on Saami museums that contest this picture of a pristine, untouched culture. These museums focus more on the creativeness and bricolage of living Saamis in a globalized world and depict Saami culture and identity as a continuously ongoing process of human invention.

\section{LITTERATUR}

Anderson, B. 1983. Imagined communities: reflections on the origins and spread of nationalism, Verso, London.

Appadurai, A. 1988. Putting hierarchy in its place. Cultural Anthropology vol 3 (1): 36-49.

Arran, 1998. Søknad om midler til basisutstilling. Brev datert 25.11.98.

Bråstad Jensen, E. 1991. Fra fornorskningspolitikk mot kulturelt mangfold, Nordkalottforlaget, Stonglandseidet.

Clifford, J. 1988. The predictament of culture. Twentieth-century ethnography, literature, and art. Harvard University Press, Cambridge, Massachusetts.

Clifford, J. 1997. Routes. Travel and translation in the late twentieth century, Harvard University Press; Cambridge, Massachusetts.

Eira, M.T. 1988. Særmuseum for samekulturen ideologien bak. Museumsnytt nr. 4, 1988:32-37.

Eidheim, H. (red.) 1999. Samer og nordmenn, Cappelen Akademisk Forlag, Oslo.

Eyo, E. 1996. Repatriation of cultural heritage: the African experience. I F.E.S. Kaplan (red), Museums and the making of "ourselves», Leicester University Press, London.

Gilberg, R. 1997. Hvem ejer museumsgenstandene? Nordisk Museologi 1997/1:117-131. 
Grasskamp, W. 1994. Reviewing the museum - or: the complexity of things. Nordisk museologi 1994/1:65-74.

Grydeland, S.E. 1996. Den sjosamiske bosetting $i$ Kvonangen fra seinmiddelalder til ny tid - en arkeologisk studie i kontraster. Hovedfagsoppgave i arkeologi, Universitetet i Tromsø.

Habermas, J. 1971. Borgerlig offentlighet. Gyldendal, Oslo.

Hall, J. V. 1982. The spoils of Empire - laying down the law: art treasures, getting the heritage home. South: Third World Magazine, January: 37-39.

Hall, S. 1992. The west and the rest: discourse and power. In S. Hall and B. Gieben (eds.), Formations of modernity, Polity Press, Cambridge.

Macdonald, S. 1996. Theorizing museums: an introduction. In S. Macdonald and G. Fyfe (red.), Theorizing museums. Representing identity and diversity in a changing world, Blackwell, Oxford.

Nilsson, M. 1982. Samerna og museerne. I E. Vesselbo og R. Gilberg (red.), Vi er samer. Laplands og Finmarkens urbefolkning, Museum Tusculanums Forlag, København.

Pennanen, J. 1998. Siida. The Sámi museum guide. Publication of the Inari Sámi Museum 1, Siida Inarin Saamelaismuseo, Inari.

Plessen, M.-P. von, 1994. Order and culture. Passages of popularization. Nordisk Museologi 1994/1: 25-30.

Pomian, K. 1990. Collectors and curiosities: Paris and Venice, 1500-1800, Polity Press, Cambridge.

Prösler, M. 1996. Museums and globalization.I S. Macdonald and G. Fyfe (red.), Theorizing museums. Representing identity and diversity in a changing world, Blackwell, Oxford.

Riegel, H. 1996. Into the heart of irony: ethnographic exhibitions and the politics of difference. I S. Macdonald and G. Fyfe (red.), Theorizing museums. Representing identity and diversity in a changing world, Blackwell, Oxford.

Rojek, C. og J. Urry (red.) 1997. Touring cultures.

Transformations of travel and theory, Routledge, London.

Said, E.W. 1978. Orientalism. Routledge \& Kegan Paul, London.

Schanche, A. 1997. Graver i ur og berg. Samisk gravskikk og religion 1000 f.Kr. til 1700 e.Kr. Dr.art. avhandling i arkeologi, Universitetet i Tromsø.

Stordahl, V. 1996. Same i den moderne verden, Davvi Girji, Karasjok.

Teigmo, M. 1976. De samiske samlinger som samisk kulturinstitusjon. Museumsnytt nr. 2, 1976:75-82.

Todorov, T. 1984. The conquest of America: the question of the other, Harper \& Row, New York.

Vindheim, G. 1994. Museum i eit tidskifte. Fortidsarv som underhaldning. Samlaget, Oslo.

Wolf, E. 1992. Europe and the people without histo$r y$, University of California Press, Berkeley.

Worsley, P. 1984. The three worlds: culture and world development. Weindenfeld \& Nicholson, London.

Young, R. 1990. White mythologies: writing, history and the west, Routledge, London.

Zachrisson, I. 1984. De samiska metalldepåerna år 1000-1350 i ljuset av fyndet från Mörtträsket, Lappland. Archaeology and Environment 3, Umeå.

NOT Norsk museumsutviklings jubileumskonferanse 8. november 1999 redovisades i skriften Når tradisjonene står $i$ veien. Där ingick en kortare version av Bjørnar Olsens text.

Björnar Olsen är professor $i$ arkeologi vid Tromsö universitet.

Adr: Institutt for Samfunnsvitenskap, Universitetet $i$ Tromse, N-9037 Tromso

Email:bjornaro@edvarda.isv.uit.no 